\title{
Frameshift Mutations in the Bax Gene Are Not Involved in Development of Ovarian Endometrioid Carcinoma
}

\author{
Shi-nian Cao, M.D., Ki-Hong Chang, M.D., Rajyalakshmi Luthra, Ph.D., Jinsong Liu, M.D., Ph.D. \\ Department of Pathology, The University of Texas Medical School-Houston (SC) and Department of \\ Pathology, The University of Texas M. D. Anderson Cancer Center (RL, JL), Houston, Texas
}

\begin{abstract}
The purpose of this study was to determine whether mutations in the Bax gene play a role in the development of ovarian endometrioid carcinoma with a microsatellite instability phenotype. We analyzed a total of 60 tumor specimens, 49 ovarian endometrioid carcinomas and 11 concurrent endometrial endometrioid carcinomas from 49 patients. Fourteen ovarian endometrioid carcinomas and 6 endometrial endometrioid carcinomas showed a microsatellite instability-high phenotype. Tumor and normal-tissue specimens from eight patients with a microsatellite instability-high phenotype colorectal carcinoma were included in this study as controls. The presence or absence of a mutation in the poly (G) 8 tract of the Bax gene was determined by polymerase chain reaction followed by direct DNA sequence analysis. A 1-base pair deletion at the poly (G) 8 tract and no expression of Bax and Bcl-2 proteins were identified in one microsatellite instability-high endometrial endometrioid carcinoma. Immunohistochemical staining for Bax and Bcl-2 proteins was negative on the tumor specimen that had this 1-base pair deletion. No mutations were found in the synchronous microsatellite instability-high ovarian endometrioid carcinoma from the same patient. In contrast, four $(50 \%)$ of the eight microsatellite instability-high sporadic colorectal carcinomas had a mutation in the poly (G) 8 tract. Although Bax plays an important role in carcinogenesis of the colorectum with microsatellite instability-high phenotype, Bax may not play a direct role in the genesis of ovarian endometrioid
\end{abstract}

Copyright (C) 2003 by The United States and Canadian Academy of Pathology, Inc.

VOL. 16, NO. 10, P. 1048, 2003 Printed in the U.S.A.

Date of acceptance: July 2, 2003.

This work was supported in part by institutional start-up funds, an institutional research grant, and a career development award from The University of Texas M. D. Anderson Cancer Center Specialized Program of Research Excellence (SPORE) in Ovarian Cancer (to J.L.).

Address reprint requests to: Jinsong Liu, M.D., Ph.D., Department of Pathology, Box 85, The University of Texas M. D. Anderson Cancer Center, 1515 Holcombe Boulevard, Houston, TX 77030-4095; fax: 713-792-5529; e-mail: jliu@mdanderson.org.

DOI: 10.1097/01.MP.0000089781.66207.D6 carcinoma, regardless of microsatellite instability status.

KEY WORDS: Bax gene, Microsatellite instability, Ovarian endometrioid carcinoma.

Mod Pathol 2003;16(10):1048-1052

Bax, the Bcl-2-associated X protein, is believed to play an important role in regulating apoptosis (1). Bcl-2 family members can be categorized into two functional subtypes: those that inhibit apoptosis (antiapoptotic) and those that promote apoptosis (proapoptotic). The antiapoptotic family members include Bcl-2, Bcl- $\mathrm{x}_{\mathrm{L}}$, Bcl-w, Al/Bfl-1, and Mcl-1. The proapoptotic members include Bax, Bcl-xs, Nbk/bik, Bak, Bad, Bid, and Noxa. Members of the Bcl-2 family proteins are involved in p53-mediated apoptosis. p53 has an upstream effect on Bax. This effect can be carried out through direct activation, causing an increase in Bax gene expression and transcription (2); however, Bax is also able to induce apoptosis in a p53-deficient background. Bcl-2 family members interact with both p53 and each other and contribute significantly to the biochemical functions involved in the regulation of apoptosis. Antagonistic reactions are present between Bcl-2 and Bax, Bid, Bak, and Bad and between Bcl-xl and Bcl-xs and Bak. Like the tumorsuppressor gene $p 53$, the Bax gene plays an important role in protecting cells from DNA damage. Any damage to the Bax gene could result in interruption of the apoptotic cascade, which can contribute to the development of cancer. For example, in breast carcinoma, lower-than-normal Bax expression correlates with a poor response to chemotherapy and short overall patient survival (3). Restoration of Bax expression in breast cancer cell lines inhibits tumorigenicity and increases sensitivity to cytotoxic drug therapy (4). The mechanism underlying reduced Bax protein expression is not clear. In one series, mutations in the Bax gene were detected in $\leq 42 \%$ of microsatellite instabilityunstable tumors without p53 mutations (5). 
Microsatellites are short, repetitive sequences of 1- to 6-base-pair (bp) subunits and are often copied incorrectly by DNA polymerases because the template and newly synthesized strands in these regions are particularly prone to misalignment. Microsatellite instability in tumors is the contraction or expansion of these repeat sequences in the tumor relative to germline (6). Microsatellite instability produces frameshift mutations if not reversed by the mismatch repair system, a guardian of genomic stability that functions to identify and repair mismatched bases during DNA synthesis (7). In human beings, $h M S H 2$, $h M L H 1$, hPMS1, hPMS2, and GTBP are mismatch repair genes. Mismatch repair is associated with microsatellite instability and frameshift mutation (8). This association is supported by the fact that mismatch repair protein expression is absent (9) or markedly reduced in most tumors exhibiting microsatellite instability $(10,11)$. The third exon of the Bax gene contains a stretch of eight consecutive $G$ residues, the poly $(G) 8$ tract, which has been described as a frequent site for frameshift mutations in cancers with a microsatellite unstable phenotype, including $51 \%(21 / 41)$ of hereditary nonpolyposis colorectal cancers, $41 \%$ (9/ 22) of other colorectal cancers, and $33 \%(5 / 15)$ of gastric cancers. Because of the morphologic similarity between hereditary nonpolyposis colorectal cancer, endometrial endometrioid carcinoma, and ovarian endometrioid carcinoma, and the high rates of microsatellite instability-high phenotypes among these tumors, we attempted to determine whether the Bax poly $(G) 8$ tract plays a role in the development of ovarian endometrioid carcinoma with a microsatellite-instability phenotype. We addressed this issue by analyzing a total of 60 tumor samples, including 49 ovarian endometrioid carcinomas and 11 concurrent endometrial endometrioid carcinomas from 49 patients.

\section{MATERIALS AND METHODS}

Matched pairs of formalin-fixed, paraffinembedded normal tissue specimen and a total of 60 tumor specimens, 49 ovarian endometrioid carcinomas and 11 concurrent endometrial endometrioid carcinomas from 49 patients, were obtained from the Department of Pathology of the University of Texas M. D. Anderson Cancer Center. The pathologic diagnosis for each tumor was confirmed by a pathologist (J.L.). Tumor was microdissected from adjacent normal tissue with an 18-gauge needle under light microscopy. DNA from each sample was extracted and analyzed for microsatellite instability using a panel of five microsatellite markers recommended by the National Cancer Institute: BAT25, BAT26, D5S346, D17S250, and D2S123. Tu- mors in which two or more markers showed instability were defined as microsatellite instability-high. Tumors in which only one marker showed instability were defined as microsatellite instability-low. Tumors in which no markers exhibited microsatellite instability were defined as microsatellite stable. The detailed characterization of microsatellite instability in ovarian endometrioid carcinoma is presented elsewhere (Liu et al., submitted).

Among the 60 tumor samples, 14 ovarian and 6 endometrial cancers were microsatellite instabilityhigh, 7 ovarian and 2 endometrial cancers were microsatellite instability-low, and the remainder were microsatellite stable. A mutation of Bax in the poly (G) 8 tract was determined by polymerase chain reaction (PCR) and subsequent direct DNA sequence analysis. The entire sequence containing the Bax poly $(\mathrm{G}) 8$ tract from nucleotides $91-184$ of the Bax gene was examined. The sense and antisense primers and their corresponding nucleotides were 5'-ATCCAGGATCGAGCAGGGCG-3' and 5'ACTCGCTCAGCTTCTTGGTG-3', respectively. The expected size of the PCR-generated sequence was $94 \mathrm{bp}$. The PCR amplification was performed for 35 cycles, each consisting of denaturation at $94^{\circ} \mathrm{C}$ for 1 minute, annealing at $55^{\circ} \mathrm{C}$ for 1 minute, and extension at $72^{\circ} \mathrm{C}$ for 2 minutes. Each $25-\mu \mathrm{L}$ PCR reaction contained $100 \mathrm{ng}$ of DNA, $200 \mu \mathrm{m}$ of dNTP, 1 unit of Taq DNA polymerase, 10 pmol of each primer, and $2.5 \mu \mathrm{L}$ of $10 \times$ PCR buffer. DNAs from eight sporadic microsatellite instability-high colorectal carcinoma were used, and their corresponding normal tissues were also included in this study as positive controls and examined for Bax mutation under the same conditions. Statistical analyses were performed using the $\chi^{2}$ test. A $P$ value of $<.05$ was considered statistically significant.

Immunohistochemical staining for Bax and Bcl-2 was performed only on tumors that had poly $(\mathrm{G})$ mutations, using an avidin-biotinylated immunoperoxidase method (15). Positive and negative controls for Bcl-2 and Bax stains were created using antibodies to Bcl-2 (1:200 dilution; Biogenex Corporation, CA) and Bax (1:20 dilution; Zymed Corporation, CA).

\section{RESULTS}

No mutations were observed in the poly $(G) 8$ tract of the 49 ovarian endometrioid carcinomas. A 1-bp deletion in the poly (G) 8 tract was found in $17 \%(1 / 6)$ of endometrial endometrioid carcinomas with a microsatellite instability-high phenotype (Fig. 1). In the positive controls, 50\% (4/8) of the cancer specimens demonstrated a mutation in the poly (G) 8 tract, whereas each adjacent nonneoplastic epithelial tissues showed no mutations. 


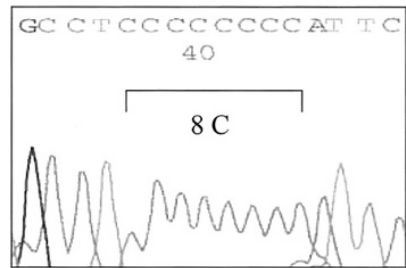

B

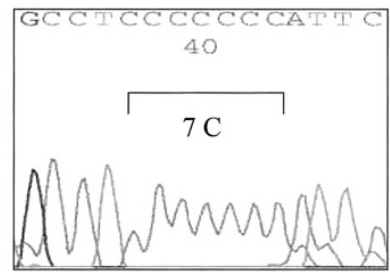

FIGURE 1. A single base deletion in the poly (G) 8 tract in the Bax gene in an endometrial endometrioid carcinoma, shown from the sequence of antisense. A, normal control. B, a 1-base-pair deletion in the Bax gene.

The same patient with the 1-bp deletion also had synchronous microsatellite instability-high ovarian endometrioid carcinoma, which was negative for the mutation.

The numbers of poly $(\mathrm{G}) 8$ tract mutations in the Bax gene of ovarian endometrioid carcinomas and endometrial endometrioid carcinomas with a microsatellite-instability phenotype are summarized in Table 1. This 1-bp deletion led to an interruption of Bax protein expression, which was confirmed by immunohistochemical analysis (Fig. 2AB). Immunohistochemical analysis also showed that Bcl-2 protein was not expressed (Fig. 2C-D). The lack of Bax protein and Bcl-2 protein staining in this Bax mutation tumor indicates that this 1-bp deletion was sufficient to abolish the Bax protein and Bcl-2 protein expression.

\section{DISCUSSION}

Microsatellite instability plays a significant role in the development of various human tumors, including ovarian carcinoma (16-19). Microsatelliteunstable tumor cells tend to have mutations in repetitive sequences throughout the genome (19). The most common mutations have been reported in the insulin-like growth factor II receptor, Bax, and RIZ genes (13, 20-22). Microsatellite instability can occur secondary to somatic mutations of mismatch repair or promoter hypermethylation of mismatch repair genes (23). The role of mismatch re- pair genes in tumorigenesis of hereditary nonpolyposis colorectal cancer has been well studied. In most cases of this cancer, affected individuals have germline mutations in one of the mismatch repair genes. Among these germline mutations, those in the hMSH2 and hMLH1 genes are associated with a microsatellite-unstable phenotype and account for the majority of these hereditary cancers (24). Mononucleotide repeat sequences within the coding regions of the genes for transforming growth factor $\beta$ I receptor, Bax, insulin-like growth factor type II, and a transcription factor involved in the APC/ $\beta$-catenin/T-cell factor pathway (TCF 4 ) have recently been demonstrated to be targets of somatic frameshift mutations that have oncogenic potential in tumor cells with defective mismatch repair genes. Hereditary nonpolyposis colorectal cancer could result from an accumulation of these somatic frameshift mutations within the genes involved in such cell functions as growth control, apoptosis, and DNA repair. Bax gene somatic frameshift mutations in the poly $(G) 8$ tract have been reported in several microsatellite instabilityhigh endometrial, gastric, colorectal, and ovarian (endometrioid and clear cell carcinoma) cancers $(12,13,24)$.

In our study, all the ovarian endometrioid carcinomas were negative for mutations in the poly $(\mathrm{G})$ 8 tract, indicating that Bax poly (G) 8 is not involved in this cancer's development. We believe that this negative finding was not caused by bias or technical error because $50 \%(4 / 8)$ of microsatellite instabilityhigh colorectal carcinomas with were positive for mutations at the poly $(G) 8$ tract.

Our results are similar to those in a report elsewhere (25) that showed a frequency of $5 \%(1 / 20)$ in Bax gene mutation in ovarian endometrioid carcinomas. Our results are in contrast to those of from Gras et al. (24), who showed Bax gene mutation in $86 \%(6 / 7)$ in ovarian endometrioid and clear cell carcinomas. The seven cases in the study by Gras et al. (24) included both ovarian endometrioid carcinomas and clear cell carcinomas with microsatellite instability-high phenotypes. In our study, we ana-

Table 1. Analysis of the Exon 3 Poly (G) 8 Tract Mutation in the Bax Gene in a Total of 60 Tumor Samples Including 49 Ovarian Endometrioid Carcinoma and 11 Concurrent Endometrial Endometrioid Carcinoma Tumors in 49 patients

\begin{tabular}{|c|c|c|c|}
\hline Tumor Type & $\begin{array}{l}\text { Number of } \\
\text { Cases }\end{array}$ & $\begin{array}{l}\text { Number of 1-bp Deletions in } \\
\text { poly (G) } 8 \text { Tract }\end{array}$ & P-Value \\
\hline Colorectal Carcinoma $(\mathrm{n}=8)$ & 8 & 4 & \\
\hline \multicolumn{4}{|c|}{ Ovarian Endometrioid Carcinoma $(n=49)$} \\
\hline Microsatellite Instability High & 14 & 0 & 0.018 \\
\hline Microsatellite Instability Low & 7 & 0 & \\
\hline Microsatellite Stable & 28 & 0 & \\
\hline \multicolumn{4}{|c|}{ Endometrial Endometrioid Carcinoma $(\mathrm{n}=11)$} \\
\hline Microsatellite Instability High & 6 & 1 & 0.363 \\
\hline Microsatellite Instability Low & 2 & 0 & \\
\hline Microsatellite Stable & 3 & 0 & \\
\hline
\end{tabular}

Statistics were performed with chi-sqaure analysis and a $P$ value $<0.05$ was considered as statistically significant. 


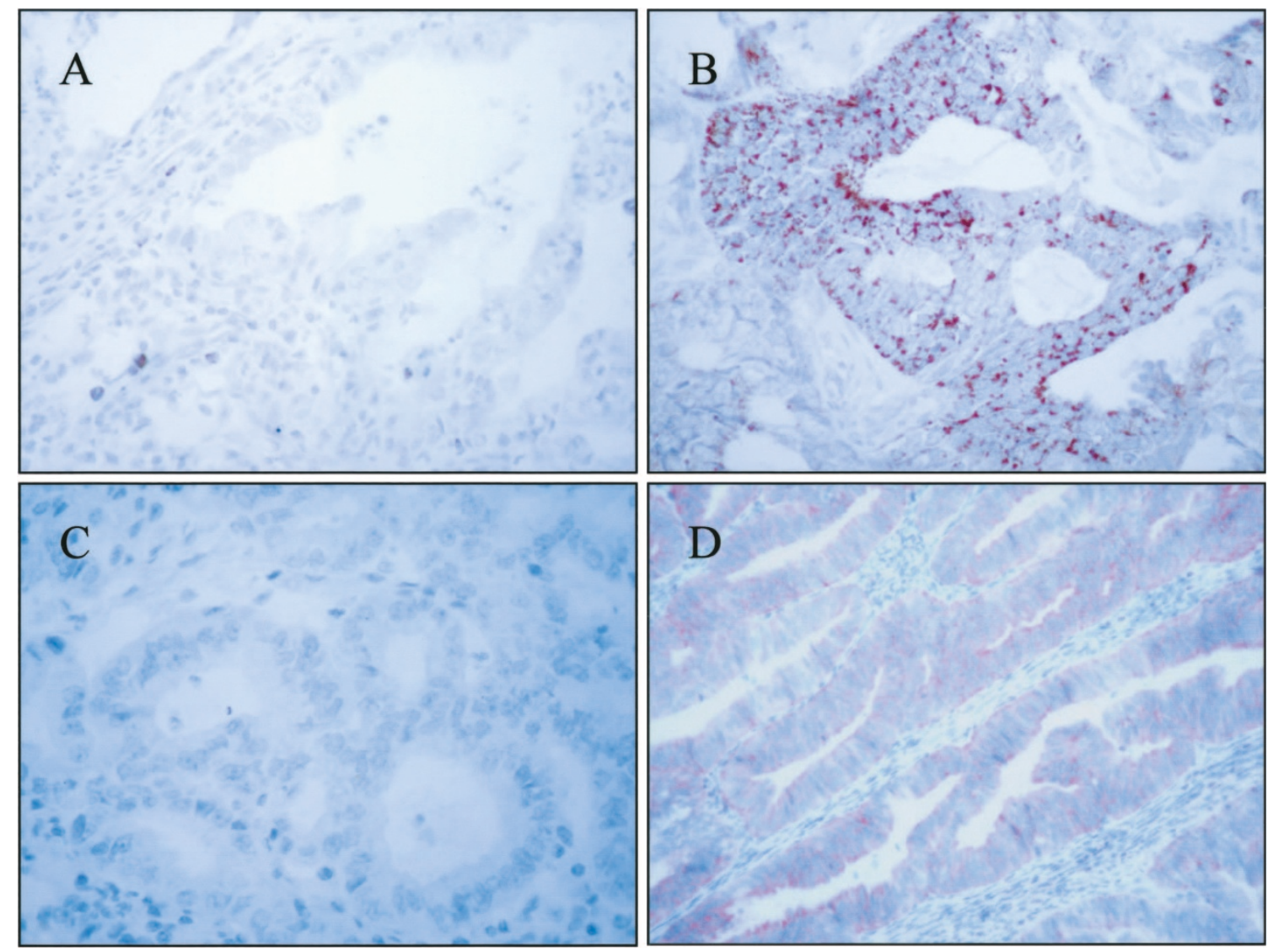

FIGURE 2. Bax and Bcl-2 protein expression in endometrial endometrioid carcinoma, with and without the Bax mutation. A and B, immunohistochemical staining for Bax, with (A) and without (B) 1-base pair deletion in Bax gene (200× magnification). C and D, immunohistochemical staining for Bcl-2, with (A) and without (B) 1-base-pair deletion in Bax gene (200× magnification).

lyzed only ovarian endometrioid carcinomas. In addition, the patient populations differed between the two studies. Our patient samples were mainly from a tertiary cancer care center in the United Sates, whereas patients in the study by from Gras et al. (24) were from Santa Creau i Sant Pau, Barcelona, Spain. Whether histologic subtype or patient ethnicity contributes to variations of Bax mutation frequency remains to be determined in future studies.

Acknowledgments: The authors thank Ms. Kathryn Carnes and Mariann Crapanzano for their editorial assistance.

\section{REFERENCES}

1. Apte SS, Mattei MG, Olsen BR. Mapping of the human BAX gene to chromosome 19q13.3-q13.4 and isolation of a novel alternatively spliced transcript, BAX delta. Genomics 1995; 26:592-4.

2. Miyashita T, Krajewski S, Krajewska M, Wang HG, Lin HK, Liebermann DA, et al. Tumor suppressor p53 is a regulator of bcl-2 and bax gene expression in vitro and in vivo. Oncogene 1994;9:1799-1805.

3. Krajewski S, Blomqvist C, Franssila K, Krajewska M, Wasenius VM, Niskanen E, et al. Reduced expression of proapoptotic gene Bax is associated with poor response rates to combination chemotherapy and shorter survival in women with metastatic breast adenocarcinoma. Cancer Res 1995;55: 4471-8.

4. Wagener C, Bargou RC, Daniel PT, Bommert K, Mapara MY, Royer HD, et al. Induction of the death-promoting gene Bax-alpha sensitizes cultured breast-cancer cells to druginduced apoptosis. Int J Cancer 1996;67:138-41.

5. Simms LA, Radford-Smith G, Biden KG, Buttenshaw R, Cummings M, Jass JR, et al. Reciprocal relationship between the tumor suppressors p53 and BAX in primary colorectal cancers. Oncogene 1998;17:2003-8.

6. Parsons R, Li GM, Longley MJ, Fang WH, Papadopoulos N, Jen J, et al. Hypermutability and mismatch repair deficiency in RER+ tumor cells. Cell 1993;75:1227-36.

7. Eshleman JR, Markowitz SD. Mismatch repair defects in human carcinogenesis. Hum Mol Genet 1996;5 Suppl:1489-94.

8. Kinzler KW, Vogelstein B. Lessons from hereditary colorectal cancer. Cell 1996;87:159-70.

9. Thibodeau SN, French AJ, Roche PC, Cunningham JM, Tester DJ, Lindor NM, et al. Altered expression of hMSH2 and hMLH1 in tumors with microsatellite instability and genetic alterations in mismatch repair genes. Cancer Res 1996;56:4836-40.

10. Leung SY, Yuen ST, Chung LP, Chu KM, Chan AS, Ho JC. hMLH1 promoter methylation and lack of hMLH1 expression in sporadic gastric carcinomas with high-frequency microsatellite instability. Cancer Res 1999;59:159-64.

11. Kim HS, Lee BL, Woo DK, Bae SI, Kim WH. Assessment of markers for the identification of microsatellite instability phenotype in gastric neoplasms. Cancer Lett 2001;164:61-8.

12. Rampino N, Yamamoto H, Ionov Y, Li Y, Sawai H, Reed JC, et al. Somatic frameshift mutations in the BAX gene in colon 
cancers of the microsatellite mutator phenotype. Science 1997;275:967-9.

13. Ouyang H, Furukawa T, Abe T, Kato Y, Horii A. The BAX gene, the promoter of apoptosis, is mutated in genetically unstable cancers of the colorectum, stomach, and endometrium. Clin Cancer Res 1998;4:1071-4.

14. Tubbs RR, Sheibani K. Immunohistology of lymphoproliferative disorder. Semin Diagn Pathol 1984;1:272-84.

15. Aaltonen LA, Peltomaki P, Leach FS, Sistonen P, Pylkkanen L, Mecklin JP, et al. Clues to the pathogenesis of familial colorectal cancer. Science 1993;260:812-6.

16. Thibodeau SN, Bren G, Schaid D. Microsatellite instability in cancer of the proximal colon. Science 1993;260:816-9.

17. Ionov Y, Peinado MA, Malkhosyan S, Shibata D, Perucho M. Ubiquitous somatic mutations in simple repeated sequences reveal a new mechanism for colonic carcinogenesis. Nature 1993;363:558-61.

18. Strand M, Prolla TA, Liskay RM, Petes TD. Destabilization of tracts of simple repetitive DNA in yeast by mutations affecting DNA mismatch repair. Nature 1993;365:274-6.

19. Abe T, Ouyang H, Migita T, Kato Y, Kimura M, Shiiba K, et al. The somatic mutation frequency of the transforming growth factor beta receptor type II gene varies widely among different cancers with microsatellite instability. Eur J Surg Oncol 1996;22:474-7.
20. Souza RF, Appel R, Yin J, Wang S, Smolinski KN, Abraham $\mathrm{JM}$, et al. Microsatellite instability in the insulin-like growth factor II receptor gene in gastrointestinal tumours. Nat Genet 1996;14:255-7.

21. Ouyang H, Shiwaku HO, Hagiwara H, Miura K, Abe T, Kato Y, et al. The insulin-like growth factor II receptor gene is mutated in genetically unstable cancers of the endometrium, stomach, and colorectum. Cancer Res 1997;57:1851-4.

22. Esteller M, Catasus L, Matias-Guiu X, Mutter GL, Prat J, Baylin SB, et al. hMLH1 promoter hypermethylation is an early event in human endometrial tumorigenesis. Am J Pathol 1999;155:1767-72.

23. Peltomäki P, Vasen HFA. Mutations predisposing to hereditary nonpolyposis colorectal cancer: database and results of a collaborative study. Gastroenterology 1997;113:1146-58.

24. Gras E, Catasus L, Arguelles R, Moreno-Bueno G, Palacios J, Gamallo C, et al. Microsatellite instability, MLH-1 promoter hypermethylation, and frameshift mutations at coding mononucleotide repeat microsatellites in ovarian tumors. Cancer 2001;92:2829-36.

25. Colella G, Vikhanskaya F, Codegoni AM, Bonazzi C, D'Incalci M, Broggini M. hMLH1 and hMSH2 expression and Bax frameshift mutations in ovarian cancer cell lines and tumors. Carcinogenesis 1998;19:691-4. 